\title{
Scenarios in Global Environmental Assessments: Key characteristics and lessons for future use
}

\author{
Detlef P. van Vuuren ${ }^{\text {a,b,*}}$, Marcel T.J. Kok ${ }^{a}$, Bastien Girod ${ }^{\text {a,b }}$, Paul L. Lucas ${ }^{\text {a }}$, Bert de Vries ${ }^{\text {a,b }}$ \\ a Netherlands Environmental Assessment Agency, PO Box 303, 3720 AH Bilthoven, The Netherlands \\ ${ }^{\mathrm{b}}$ Department of Geosciences, Utrecht University, Heidelberglaan 2, 3584 CS Utrecht, The Netherlands
}

A R T I C L E I N F O

\section{Article history:}

Received 4 March 2011

Received in revised form 25 May 2012

Accepted 1 June 2012

Available online 4 July 2012

\section{Keywords:}

Scenarios

Integrated assessment

Global Environmental Assessment

\begin{abstract}
A B S T R A C T
Over the last 10 years a large set of global environmental assessment studies has been published that include scenario projections. Comparison of these studies shows that there is actually a limited set of scenario families that form the basis of many scenarios used in different environmental assessments. Mapping these scenario families allow a simpler comparison across the different assessments. The fact that many assessments can be positioned within these families gives some confidence of their relevance. It is also noticeable that several recent assessments have been focusing on more focussed policyscenarios as variant to a single baseline. This is partly a response to a different stage in the policy-making process. While there are clear advantages of both categories of scenarios (explorative scenarios and baseline/policy variants), it might be important to test the robustness of scenario outcomes of the policyscenario approach against the different storyline scenario-families identified in this paper.
\end{abstract}

(c) 2012 Elsevier Ltd. All rights reserved.

\section{Introduction}

Global Environmental Assessments (GEAs) have become a key instrument to inform policy-makers on global environmental and sustainability problems, both with respect to their importance and possible response options (Clark et al., 2006). Within the assessments, looking into different possible futures forms a key element (Ash, 2010; Jäger et al., 2009). This is mostly because inertia plays a key role in environmental problems: today's decisions are likely to have lasting long-term consequences. One way tool to explore future development is prediction. Prediction is possible if systems are well known and can be observed in controlled and reproducible situations. Unfortunately, this is rarely the case for environmental problems: they are characterized by complex causal relationships, limited knowledge and a high level of uncertainty. Instead, scenario analyses can be used. In contrast to prediction, scenario analysis does not focus on the most likely development but on an assessment of pathways of events under a set of key assumptions ('what if'?). These assumptions allow to set aside some of the uncertainties that complicate more exact statements on future behavior. Earlier, scenarios have been defined as plausible descriptions of how the future might develop, based on a coherent and internally consistent set of assumptions ("scenario

\footnotetext{
* Corresponding author at: Netherlands Environmental Assessment Agency, PO Box 303, 3720 AH Bilthoven, The Netherlands. Tel.: +31 302742046.

E-mail address: Detlef.vanvuuren@pbl.nl (D.P. van Vuuren).
}

logic") about the key relationships and driving forces (e.g. rate of technology change, value change or prices) (de Vries and Petersen, 2009; Nakicenovic et al., 2000).

The use of scenarios is not new. Analysts often mention the work of Kahn and Wiener (1967) and Shell planning as pioneering work in scenario analysis (van Asselt et al., 2010). More specifically for GEA, the Limits to Growth report of the Club of Rome played an important role in introducing the use of scenarios (Meadows et al., 1972) (although they did not use the term scenarios, but their conditional forward calculations take a similar role as the scenarios now presented in GEAs). In the last 10-15 years, scenario analysis has become very popular in GEA. Many GEAs now extensively use scenario analysis, such as IPCC's Assessment Report (IPCC, 2001, 2007), UNEP's Global Environmental Outlook (UNEP, 2002, 2007), the International Assessment on Agricultural Knowledge, Science and Technology Development (IAASTD) (Watson, 2008) and the Millennium Ecosystem Assessment (MEA) (MA, 2005).

Obviously, this work has led to a wide body of experience. Some studies have provided an overview of this experience, but these studies often focused on a limited set of studies and/or in a rather descriptive way (Kok et al., 2008, 2009; Leemans, 2008; Mitchell et al., 2006; NRC, 2007; Raskin et al., 2005; Rothman et al., 2009). The question arises whether (1) the information of the scenario analysis in different assessments and (2) their methods can be directly compared? The answer could be valuable for the various users of the assessments. For instance, decision-makers on climate change might be interested in using the MEA scenarios to get information on land use and nitrogen cycles, but would like to use 
this in conjunction with the IPCC scenarios normally used in their domain. Similarly, researchers investigating agricultural issues on the basis of IAASTD work might be interested in learning from the climate scenarios from the IPCC. On first sight, there are clear differences: GEAs focus on different issues, have different user groups and follow different methodologies. However, as we will show in the article there are also many elements in common. In that light, we aim to provide a comparison of the scenarios used in the literature by: (1) discussing the use of scenarios in different assessments in relation to the main characteristics of the assessment, (2) comparing the storylines and main assumptions behind the different scenarios and (3) discussing important trends that can be observed in the main scenario methodology in relation to the stage of policy making.

The paper is structured as follows. In Section 2, we introduce several important GEAs that have been published in the recent years (including global studies that have been performed by international expert teams). We also discuss different ways to categorize scenarios and indicate how the various GEAs relate to these categories. In Section 3, we discuss the scenarios that are used in these studies and classify them in scenario-families (and thus provide a way to categorize them on the basis of content). Finally, in Section 4 we take a more forward looking perspective and indicate possible lessons for future assessments.

\section{Previous assessments}

\subsection{Scenario-based GEAs 2000-2008}

Pulver and van Deveer (2009) recently identified important scenario studies for a wide range of environmental problems (18 in total) and, in addition, 1241 scenario articles in the scientific literature. From their list of scenario studies, we have selected the most prominent assessments published in the 2000-2010 period and added some scenario studies specifically addressing energy and land use given both the prominence of these issues for global environmental change in general, but also because of the prominent position of these studies (Table 1 ). Some of the terms used in this paper are defined in Table 2.

Four scenario studies published in the early 2000s are the Global Scenario Group (GSG)'s work on Great Transitions (Raskin et al., 2002, 2005), the IPCC Special Report on Emission Scenarios (SRES) (Nakicenovic et al., 2000) and UNEP's Third Global Environmental Outlook (GEO3) (UNEP, 2002) and the World Water Vision work (Cosgrove and Rijsberman, 2000). The GSG work focused on a set of very different trajectories for world development, ranging from a transition towards sustainable development (Great Transitions) to a world dominated by conflict (Barbarisation). The GSG work mostly focus on the scenario storyline, with relatively little quantification. The IPCC SRES scenarios form a nice contrast as here the 'storylines' are much shorter and much more emphasis has been put on quantification. The SRES scenarios have been extensively used in subsequent work in climate research to explore climate consequences, impacts and options for mitigation (the latter have sometimes referred to as post-SRES scenarios). The scenarios in the third study, UNEP's GEO-3, focused on a wide range of different environmental problems. The work takes a middle position in terms of storyline/quantification. This approach has also been followed in the follow-up work for GEO-4 (UNEP, 2007). Clearly, both GEO-3 and GEO-4 have used the GSG and SRES scenarios as input (as stated in the reports). The GEO scenarios have also been used in regional GEOs published for example in Latin America and the Caribbean, Africa and West Asia (UNEP, 2006, 2010a, 2010b) and do provide an interesting example of the further use of global scenarios at the regional level. Finally, the scenarios developed for the World Water Vision focus on water scarcity using quantification to support the underlying storylines.

In the 2005-2008 period, a new set of assessment reports was published. In addition to the GEO-4, this included the Millennium Ecosystem Assessment (on ecosystem services) (Carpenter and Pingali, 2005), the International Assessment of Agricultural Science and Technology Development (short title: the Agriculture Assessment) (on agriculture) (Watson, 2008), the OECD Environmental Outlook to 2030 (on environmental problems in major country groupings) (OECD, 2008), and the Comprehensive Assessment on Water Management in Agriculture (on water) (CA, 2007).

We have added to these GEAs, some more sectoral studies: i.e. IEA's World Energy Outlook (IEA, 2008) and FAO's reports on longterm agriculture development: Agriculture towards 2015/2030 (Bruinsma, 2003) and Agriculture towards 2030/2050 (FAO, 2006).

\subsection{Different type of scenarios}

Several authors have discussed methods to classify scenarios with respect to their general design and development process such as Henrichs et al. (2010), van Asselt et al. (2010), van Vuuren (2007) and Wilkinson and Eidinow (2008). We will briefly discuss some of these scenario types in relation to the use of scenarios in GEAs.

\subsubsection{Scenario versus forecast}

A first important distinction found in the literature with respect to scenarios, or better: projections in general, concerns the treatment of uncertainty. As indicated in the introduction, we follow the tradition to reserve the word 'scenario' for exploration of different futures where statements on probability are avoided by making statements of possible developments conditional upon fundamental assumptions (Henrichs et al., 2010; Nakicenovic et al., 2003). For an assessment of most likely development, we instead use the word 'forecast'. Forecasts can only be made for relatively well-known and well-defined systems. As indicated in the introduction, this is not a situation typical for environmental systems. Large uncertainties originate from complexity, lack of knowledge but also the ability of humans to imagine future and learn from past experiences. Given the fact that all GEAs have a long time horizon and describe the evolution of complex system, all GEAs use scenario rather than forecast methods.

\subsubsection{Deterministic versus probabilistic scenarios}

In relation to the treatment of uncertainty, the scenario literature also distinguishes between a deterministic and a probabilistic scenario approach (Henrichs et al., 2010; van Vuuren, 2007). The probabilistic approach aims to specify the probability of different trends by attaching probability-distribution functions (pdf) to the input parameters. This approach has been regularly applied in scientific papers (O'Neill, 2004; Richels et al., 2004; van Vuuren et al., 2008), but has so-far not been used in any of the GEAs. An important reason for this is that many important parameters are so fundamentally unknown that it is not even possible to attach meaningful probability density functions to them. In such cases, spanning the uncertainty space seems more meaningful.

\subsubsection{Process versus product orientation}

A second dimension used in distinguishing scenarios refers to the focus on process versus product (Hulme and Dessai, 2008; Major and Cordey-Hayes, 2000). If scenarios are made to support a very specific decision (e.g. for decisions of a single company such as Shell (see also Garb et al., 2008), the scenario development process can be at least as important for the user as the product: the user can be directly included in the development process and learn from the experience of scenario development and feedback. Most GEAs, 
Table 1

Overview of global scenario studies.

\begin{tabular}{|c|c|c|c|c|c|c|c|c|}
\hline & $\begin{array}{l}\text { Global Scenario } \\
\text { Group }\end{array}$ & IPCC-SRES & IPCC-TAR/AR4 & UNEP GEO3/GEO4 & MA & FAO AT2030/2050 & CA & IAASTD \\
\hline $\begin{array}{l}\text { Key reference + } \\
\text { website }\end{array}$ & $\begin{array}{l}\text { http://www.gsg.org/ } \\
\text { (Raskin et al., 2002) }\end{array}$ & $\begin{array}{l}\text { http://www.ipcc.ch/ } \\
\text { ipccreports/sres/ } \\
\text { emission/ (Nakicenovic } \\
\text { et al., 2000) }\end{array}$ & $\begin{array}{l}\text { http://www.ipcc.ch/ } \\
\text { (IPCC, 2001, 2007) }\end{array}$ & $\begin{array}{l}\text { www.unep.org/geo } \\
\text { (UNEP, 2002, 2007) }\end{array}$ & $\begin{array}{l}\text { http://www. } \\
\text { millenniumassessment. } \\
\text { org/en/index.aspx } \\
\text { (MA, 2005) }\end{array}$ & $\begin{array}{l}\text { ftp://ftp.fao.org/docrep/ } \\
\text { fao/009/a0607e/ } \\
\text { a0607e00.pdf } \\
\text { (FAO, 2006) }\end{array}$ & $\begin{array}{l}\text { http://www.iwmi.cgiar. } \\
\text { org/assessment/ (CA, 2007) }\end{array}$ & $\begin{array}{l}\text { http://www. } \\
\text { agassessment.org/ } \\
\text { (Watson, 2008) }\end{array}$ \\
\hline Focus & $\begin{array}{l}\text { Sustainable } \\
\text { development }\end{array}$ & $\begin{array}{l}\text { Greenhouse gas } \\
\text { emissions }\end{array}$ & $\begin{array}{l}\text { Climate change, } \\
\text { causes and impacts }\end{array}$ & $\begin{array}{l}\text { Global environmental } \\
\text { change }\end{array}$ & Ecosystem services & Agriculture & Water and agriculture & Agriculture \\
\hline Initiated by & $\begin{array}{l}\text { Global Scenario } \\
\text { Group }\end{array}$ & IPCC & IPCC & UNEP & Individual researchers & FAO & $\begin{array}{l}\text { CGIAR via the Challenge } \\
\text { Program on Water and } \\
\text { Food }\end{array}$ & $\begin{array}{l}\text { IAASTD (secretariat } \\
\text { provided by World } \\
\text { Bank) }\end{array}$ \\
\hline $\begin{array}{l}\text { Key issues } \\
\text { focused at }\end{array}$ & Multiple & $\begin{array}{l}\text { Energy, land use, } \\
\text { emissions }\end{array}$ & $\begin{array}{l}\text { Climate, energy, land } \\
\text { use, emissions }\end{array}$ & \multirow{2}{*}{$\begin{array}{l}\text { All international } \\
\text { environmental issues } \\
\text { Environmental policies } \\
\text { of national governments + } \\
\text { UNEP }\end{array}$} & Ecosystems and drivers & $\begin{array}{l}\text { Agriculture trends and } \\
\text { policies }\end{array}$ & Water use, agriculture & $\begin{array}{l}\text { Development, R\&D, } \\
\text { agriculture }\end{array}$ \\
\hline $\begin{array}{l}\text { Policy process } \\
\text { in focus }\end{array}$ & Not explicit & $\begin{array}{l}\text { UNFCCC/Climate } \\
\text { policies of national } \\
\text { governments }\end{array}$ & $\begin{array}{l}\text { UNFCCC/Climate } \\
\text { policies of national } \\
\text { governments }\end{array}$ & & $\begin{array}{l}\text { Various international } \\
\text { conventions/national } \\
\text { governments }\end{array}$ & $\begin{array}{l}\text { Agricultural policies of } \\
\text { national governments }\end{array}$ & $\begin{array}{l}\text { Agricultural policies of } \\
\text { national governments }\end{array}$ & $\begin{array}{l}\text { Agricultural policies } \\
\text { of national } \\
\text { governments }\end{array}$ \\
\hline Own research? & $\begin{array}{l}\text { Scenario } \\
\text { development }\end{array}$ & $\begin{array}{l}\text { Assessment of existing } \\
\text { literature + scenario } \\
\text { development }\end{array}$ & $\begin{array}{l}\text { Assessment of } \\
\text { existing literature, } \\
\text { and specifically } \\
\text { SRES-based analysis }\end{array}$ & Scenario development & $\begin{array}{l}\text { Assessment of existing } 1 \\
\text { iterature }+ \text { scenario } \\
\text { development }\end{array}$ & Scenario development & $\begin{array}{l}\text { Assessment of existing } \\
\text { literature + scenario } \\
\text { development }\end{array}$ & $\begin{array}{l}\text { Assessment of } \\
\text { existing literature }+ \\
\text { scenario } \\
\text { development }\end{array}$ \\
\hline \multirow[t]{2}{*}{ Approach } & $\begin{array}{l}\text { Strong focus on } \\
\text { storyline, supported } \\
\text { by quantitative } \\
\text { accounting system }\end{array}$ & $\begin{array}{l}\text { Modeling supported by } \\
\text { simple storylines. } \\
\text { Multiple models } \\
\text { elaborate the same } \\
\text { storyline to map out } \\
\text { uncertainties }\end{array}$ & $\begin{array}{l}\text { Summary of scenario } \\
\text { literature }\end{array}$ & $\begin{array}{l}\text { Storylines and modeling } \\
\text { on the basis of linked } \\
\text { models }\end{array}$ & $\begin{array}{l}\text { Storylines and modeling; } \\
\text { modeling on the basis of } \\
\text { linked models }\end{array}$ & $\begin{array}{l}\text { Single projection, mostly } \\
\text { based on expert judgement }\end{array}$ & $\begin{array}{l}\text { Storylines and modeling; } \\
\text { modeling on the basis of } \\
\text { linked models }\end{array}$ & $\begin{array}{l}\text { Baseline and } \\
\text { alternative scenarios; } \\
\text { modeling on the } \\
\text { basis of linked } \\
\text { models }\end{array}$ \\
\hline & & \multicolumn{2}{|c|}{ OECD-Environmental Outlook } & \multicolumn{2}{|l|}{ IEA-WEO } & & \multicolumn{2}{|c|}{ World Water Development Report } \\
\hline \multicolumn{2}{|l|}{$\begin{array}{l}\text { Key reference + } \\
\text { website }\end{array}$} & \multicolumn{2}{|c|}{$\begin{array}{l}\text { http://www.oecd.org/document } \\
\text { /20/0,3343,en_2649_34283_ } \\
\text { 39676628_1_1_1_37465,00.html } \\
\text { (OECD, 2008) }\end{array}$} & \multicolumn{2}{|c|}{$\begin{array}{l}\text { http://www.worldenergyoutlook.org/ } \\
\text { (IEA, 2008) }\end{array}$} & & \multicolumn{2}{|l|}{ www.unesco.org/water/wwap } \\
\hline Focus & & \multicolumn{2}{|c|}{ Global environmental problems } & \multicolumn{2}{|l|}{ Energy } & & \multicolumn{2}{|c|}{ Water, environmental problems and development } \\
\hline Initiated by & & \multicolumn{2}{|l|}{ OECD } & \multicolumn{2}{|l|}{ IEA } & & \multicolumn{2}{|c|}{ World Water Assessment Programme (WWAP) } \\
\hline $\begin{array}{l}\text { Key issues } \\
\text { focused at }\end{array}$ & & \multicolumn{2}{|c|}{$\begin{array}{l}\text { Land use, energy, climate, } \\
\text { air pollution, water, fisheries }\end{array}$} & \multicolumn{2}{|c|}{ Energy, energy security, climate } & & \multicolumn{2}{|c|}{$\begin{array}{l}\text { Drivers of change, use of resources, state of } \\
\text { resources, options to respond to a changing world }\end{array}$} \\
\hline $\begin{array}{l}\text { Policy process } \\
\text { in focus }\end{array}$ & & \multicolumn{2}{|c|}{$\begin{array}{l}\text { National governments }+ \text { OECD f } \\
\text { orum }\end{array}$} & \multicolumn{2}{|c|}{$\begin{array}{l}\text { Energy and climate policy } \\
\text { of national governments }\end{array}$} & & \multicolumn{2}{|c|}{ All levels including non-governmental bodies } \\
\hline Own research? & & \multicolumn{2}{|c|}{ Scenario development } & \multicolumn{2}{|c|}{ Scenario development } & & \multicolumn{2}{|c|}{$\begin{array}{l}\text { Summary of scientific literature; expert groups. } \\
\text { Case studies from WWAP }\end{array}$} \\
\hline Approach & & \multicolumn{2}{|c|}{$\begin{array}{l}\text { Baseline and alternative } \\
\text { scenarios; modeling on the } \\
\text { basis of linked models }\end{array}$} & \multicolumn{2}{|c|}{$\begin{array}{l}\text { Baseline and alternative } \\
\text { scenarios }\end{array}$} & & \multicolumn{2}{|c|}{$\begin{array}{l}24 \text { UN agencies; coordination by WWAP (UNESCO); } \\
\text { input in writing teams from universities, individual } \\
\text { experts, professional organisations, NGOs }\end{array}$} \\
\hline
\end{tabular}


Table 2

Terminology used in the paper.

\begin{tabular}{|c|c|}
\hline Term & Description \\
\hline Scenario & $\begin{array}{l}\text { Plausible descriptions of how the future might develop, as based on a coherent and internally consistent set of assumptions } \\
\text { ("scenario logic") about the key relationships and driving forces }\end{array}$ \\
\hline Storyline & Qualitative description of future development. \\
\hline Baseline & $\begin{array}{l}\text { Scenario that describes plausible future developments in the absence of explicit new policies for a specific issue. Baseline scenarios } \\
\text { can, include new policies for other issues. Baseline scenarios are typically used as reference scenarios for exploring the effectiveness } \\
\text { of intervention scenarios }\end{array}$ \\
\hline $\begin{array}{l}\text { Intervention scenarios } \\
\quad \text { (alternative policy scenarios) }\end{array}$ & $\begin{array}{l}\text { Synonyms for scenarios illustrating the consequence of an intervention or aiming at a certain target of reduction in environmental } \\
\text { impacts. }\end{array}$ \\
\hline Business-as-usual & Non-intervention scenarios. It assumes only reactive policies (no SD policies) \\
\hline Intermediate & $\begin{array}{l}\text { Takes an intermediate position within the whole set of scenarios. Makes only sense as intermediate-storyline, because of the } \\
\text { difficulty of weighting quantitative intervention scenarios. Is however only useful for non-SD topics like future IT use }\end{array}$ \\
\hline Back-casting & Scenario technique starting with a state in the future identifying possible paths back to the current state \\
\hline Probabilistic & Scenario technique attaching probabilities on the different outcomes \\
\hline Participation & Involvement of stakeholders in the scenarios development \\
\hline
\end{tabular}

however, are communicated via reports to a rather diffuse audience of scientists and decision-makers (Wilkinson and Eidinow, 2008). This implies that the product is typically more important than the process. In that context it should be noted that while GEAs have mostly a single constituent organization, this organization is not the (only) intended client. For instance, UNEP's Global Environmental Outlook targets a far broader audience than UNEP's Governing Council alone. If the product is more important than the process, transparency and legitimacy need to be important scenario features in order to ensure relevance for the user community. Also the quality of the product is an essential element (van Asselt et al., 2010). Garb et al. (2008) refer in this context to the 'clumsy hand-off' of GEA scenarios, risking to provide products that are not readily used by planners and policymakers.

\subsubsection{Participatory approaches}

Both product and process oriented assessments can include participatory approaches in which potential users work together with scenario developers. Such, participation can ensure that scenarios can be targeted better to the user needs and also use available knowledge outside the group of directly involved experts. However, participatory process may run the risk of loosing more general applicability. Again, the rather vague audience group of most GEAs implies that participation is usually restricted to specific review moments. Such review processes may be organized through formal governmental processes or less formal workshops. The MEA, for instance, organized a number of informal sessions with stakeholders both in the initial phases of the process as near the ending of it. Earlier, the lack of participation has been mentioned as a weaknesses of GEA exercises (Garb et al., 2008; Parson, 2008).

\subsubsection{Qualitative versus quantitative scenarios}

The next distinction, already introduced in Section 2.1, is the use of quantitative (model) and qualitative information (storylines) (Henrichs et al., 2010; Raskin et al., 2005; Raskin, 2005). Since the publication of the SRES scenarios (Nakicenovic et al., 2000) it has become popular to combine these two elements. Here, storylines provide a certain logic to the multiple assumptions and to help to define possible developments for those areas where formal modeling is not meaningfully possible due to ignorance and complexity. Storylines have also proven to be an appealing method to derive information at different scales or for different topics (e.g. regional scenarios nested within global storylines). The contribution of quantification (modeling) is to add scientific rigor, assuming that relevant and reliable information is available, and also to strengthen communication through clear definitions and rules (Henrichs et al., 2010).

\subsubsection{Explorative versus normative scenarios}

A further distinction is the one between explorative (or strategic) versus normative scenarios. Explorative scenarios are meant to explore a wide range of possible futures, often to widen the scope of options considered by users (agenda-setting; strategy development). In contrast, normative scenarios focus on the impacts of implementing a more narrowly defined set of goals or policy options often contribute to operational policy-decisions (Henrichs et al., 2010). The methods applied also differ. For the former, usually a set of widely contrasting scenarios is used to explore a range of possible future developments as a function of diverging assumptions for population, income growth and technology development. The latter is typically based on a central projection in which the current trends continue (assuming no new policies will be implemented), which is contrasted with a set of variants that evaluates the impact of specific policy interventions. The central projection is often called a reference, baseline or businessas-usual scenario. In the remainder of this paper, we refer to the first approach as 'explorative scenario approach' - while we refer to the second as 'policy-scenario approach'. Both approaches are used in GEAs.

It should be noted that the policy-scenario approach typically uses scenarios that are formulated in more technical, quantitative terms (and thus have less storyline elements). The baseline itself is sometimes even not considered an interesting product: what matters is the impact of the policy intervention compared to the baseline. While the method provides simplification and focus, this comes at a cost in case the policy-actions studied are smaller than the range of possible outcomes due to uncertainties in baseline assumptions, or if the effectiveness of the policy interventions is itself to a large extent dependent upon the very baseline assumptions.

\subsubsection{Forecasting versus backcasting}

The scenario literature also distinguishes forecasting and backcasting scenarios (Henrichs et al., 2010). While the first defines scenarios on the basis of a set of imposed rules defined from the base year onwards, the second approach defines scenario pathways only after first describing the end-points and reasons back from these end-points towards short-term decisions to make these changes happen (Robinson, 1982, 1990; Dreborg, 1996). The forecasting approach is often combined with the explorative scenario approach, while the policy-scenario approach can be more easily combined with the backcasting approach (but other combinations are possible).

\subsubsection{Other distinctions}

A different distinction is made by van Asselt et al. (2010). This distinction is partly related to our earlier distinction between 
explorative and policy-scenario approach; they distinguish between the 'speaking-truth-to-power' perspective to scenario development vis-à-vis the 'arena' perspective. While the former aims to provide a clear, scientific answer to a specific policyquestion (and legitimize decision-making), the second perspective aims to use scenarios as a mean to facilitate debate. Again the learning process in understanding and analyzing potential futures and the associated debate among stakeholders is more important than the scenario product itself (and in that sense, it relates to the process/product distinction made earlier). Wilkinson and Eidinow (2008) develop a similar distinction, recognizing "problem-focused scenarios" (similar to the "speaking-truth-to-power" perspective), "actor-centric scenarios" (intermediate category, focused on a specific organization) to "reflexive interventionist/multi-agent-based scenarios". The latter resembles the 'arena' category identified by van Asselt et al. Wilkinson and Eidonow argue that the last, new, approach is most suitable for environmental problems with large uncertainties and conflicting stakes.

Finally, the terms saliency, credibility and legitimacy have been proposed as possible criteria to classify scenarios (Cash et al., 2003; Girod et al., 2009). Saliency refers to the relevance and comprehensibility of the scenarios for political decision-makers and other scenario users (including scientists). Credibility is concerned with the scientific adequacy of the technical component of the scenarios spelt out in the literature. Legitimacy refers to transparency, participation and fairness of the scenario construction process. Obviously, for each scenario all three elements are required. Still, focus on these elements might be different based on the type of scenario as will be discussed further. In fact to some degree there might be a trade off. For instance, while increasing government participation is important to improve the legitimacy and therewith relevance of the scenarios, too much government involvement may lead to loss of credibility and saliency.

\subsection{GEAs and types of scenarios used}

In Table 1, we have indicated some important characteristics of the scenarios used in international assessments. A large number of different scenarios have been constructed in the various GEAs, including for instance more than 25 different baseline. Interestingly, all international assessment studies included in Table 1 for the period 2000-2005 have been based on the explorative scenario approach, using both storylines and quantification. Since 2005, however, all GEAs listed in Table 1 have used the baseline/policy scenario approach. We will discuss this important observation further in Section 4. The observation is even more remarkable the explorative approach was in fact introduced in response to the simple baseline/alternative scenarios popular at the time. For instance, the first set of IPCC scenarios consist of a set of fully quantitative, sensitivity runs without any storyline (Leggett, 1992). This is not to say that storyline-based approaches were not used. Two important examples of early explorative, storyline/quantification-based scenario studies include the so-called Shell scenarios and the work of Rotmans and de Vries (1997).

Another observation is that the scenarios used in GEAs are developed by a relatively small community, in which social scientists are usually underrepresented. As an indication for the latter, only $10 \%$ of scenario publications in the academic literature is published in social science journals (Pulver and van Deveer, 2009). Partly related to the focus on natural science issues and quantitative analysis, Garb et al. (2008) signal a growing imbalance between the technical sophistication of the modeling for scenarios and the continued simplicity of the social scientific foundations of the narratives to which they are coupled. When scenario analysis tends to focus more on policy-responses than on exploring alternative issues, the inclusion of social science and governance issues seem to become more-and-more important. It is therefore important to ensure a more extensive, high-quality social science involvement in the future.

Table 1 shows that there are other important differences across the scenario studies. One distinction concerns the coupling to a clear policy decision process. The IPCC assessments, first of all, are directly linked to the UNFCCC process and follow a rather strict approval procedure by countries to improve their legitimacy. In contrast, the MEA and the IAASTD are not directly linked to international policy processes and for them also the role of governments is less clearly defined (Leemans, 2008). Several other assessments are initiated by a single organization, but indirectly target a much wider audience of member states (OECD, UNEP, IEA, FAO). These institutional settings and stakeholder participation obviously have also implications for the design and content (including certain biases) of these assessments (de Vries and Petersen, 2009; Kok et al., 2008).

In IPCC assessments, user-involvement (in the form of governments) is organized at four key moments (design, second and final review round, final plenary) and users are finally asked to approve its publication. This high involvement results in a high level of legitimacy of the IPCC assessments (Leemans, 2008). This may contribute to the extensive use of the IPCC scenarios in literature and policy-making. It should be noted, however, that in contrast to the 2000 SRES scenarios, the new round of climate scenarios will not be "developed" anymore by IPCC, but directly by the modeling community. The argument here is that the government approval can also constrain the scenarios and, moreover, IPCC's mandate is to assess the literature and not to be involved in research itself (Moss et al., 2010). Another factor that plays a role is the reputation of the institutes and scientists involved in the scenario development. Again, taking the IPCC scenarios as an example - many well known scientists in scenario development were involved in the producing the SRES scenarios, including people from, for instance, IIASA and Shell, two organizations well-known at the time for their work on global scenarios (adding to credibility). The focus on credibility and legitimacy to some degree provides a trade-off with saliency (Girod et al., 2009; Leemans, 2008). An obvious example includes the scenario names of the SRES. While all other global scenario report use illustrative names to emphasize saliency, it was decided in the IPCC assessment to use merely numbers and letters to avoid any normative association (cf. Table 4). In this way, the disagreement about the (details of) the normative content remained obscure.

Something that is hardly found in GEAs are scenarios that deliberately explore extremes and/or surprises. As such, one may define many of the scenarios as 'extended presents' (Nowotny, 2008). This choice allows for a relatively clear relationship between current ideas and trends and the scenario outcomes, which is helpful as scenarios often need to support present-day decisions. Still, it does imply that the range of possible futures that are considered is significantly reduced. Obviously, the use of 'surprise-free' futures is strongest in scenario exercises that follow the baseline/alternative scenario approach.

Another conclusion that might be drawn from Table 1 is that quite a large number of GEAs are published. The question has been raised if we could have done with less scenario-exercises or what the 'optimal number of GEAs' could be, given limitations in both financial and human resources (Kok et al., 2008). This question is very hard to answer. First of all, most assessment have a specific niche (as can also be inferred from Table 1). Secondly, one may argue that GEAs form part of a certain 'beat', i.e. together they are better able to get a certain message across than each study individually (van Asselt et al., 2010). In that context, a possible harmonization or reduction of GEA efforts would, in our view, be a useful debate. 


\section{Common scenario elements}

All of the international assessments highlighted above have identified detailed assumptions about the future developments of key driving forces and reflected on a number of underlying uncertainties about how the global context may change over the coming decades. As the number of uncertainties about plausible or potential future developments is vast, it would clearly be possible that the scenarios across the different assessment would not be comparable. However, it seems that a limited number of key archetypical scenarios reappear in several recent international assessments. In this paper, we will further use the word "scenario families" for these scenario archetypes. This word originates from IPCC-SRES report, but the classification of the families as done here are not entirely equal to those in SRES. The word "scenario family" denotes a set of scenarios in the literature that seem to share a very similar scenario storyline or logic (i.e. basic underlying assumption, see de Vries and Petersen, 2009) resulting as well in a similar kind of quantification. Other authors have earlier noted that such scenario families exist in the literature (Nakicenovic et al., 2000; Raskin et al., 2005). Cumming et al. (2005a) use the typology made by Raskin et al. (2005). Here, we expand on the scheme developed by these earlier studies (Nakicenovic et al., 2000; Raskin et al., 2005), recognizing a total of 6 scenario families in the current literature, that do not only share assumptions on/storyline for key uncertainties, but also result in more-or-less similar outcomes. Still, the exact elaboration of each individual scenario both in terms of storyline and/or quantification may also show clear differences as these are "broad brush" categorization.

Key elements in which scenarios differ include the following: (1) a risk prone or risk averse approach to environmental degradation and feedbacks (resulting in pro-active or reactive environmental policy), (2) a global or regional focus on primary drivers and ecosystems (resulting, among others, in different management style), (3) the position compared historically observed trends (deviation or continuation) and (4) the attitude towards cooperation and competition.

Given these key-elements, in existing scenarios the following six scenario families can be observed: (1) the economictechnological optimism/conventional markets scenarios, (2) the reformed market scenario, (3) the global sustainability scenario, (4) the regional competition/regional markets scenarios, the (5) regional sustainable development scenarios, (6) and the businessas-usual/intermediate scenarios. These categories resemble those of (Raskin et al., 2005): market forces (1), reformed market (2), value change (3), higher fences (4) and multipolar world (5). We have summarized the main characteristics of the scenario families in Table 3. Below, we briefly discuss each family. It should be noted that nearly all GEAs indicate that their scenarios are caricatures with low likelihood, in the sense that the future will be almost certainly be based on elements from more than one scenario family - even for the business-as-usual case. Indeed, any archetypical scenario is unlikely to become reality as its appearance will induce forces that will counteract the underlying developments (de Vries, 2006). In this way, the future will unfold in ways which are difficult to predict. In most families both positive elements and possible risks can be identified (as indicated in the text below).

\subsection{Economic optimism/conventional markets scenarios}

This scenario family refers to scenarios with a strong focus on the mechanism of competitive, efficient market and associated rapid economic growth. Other important elements are the increase of free trade leading to a single global market (based on phasing out of subsidies and trade barriers) and the assumption that further deregulation and privatisation encourage efficiency and innovation. The scenario typically assumes rapid technology development and partial convergence of income levels across the world. Economic growth is assumed to coincide with low population growth (given a rapid drop in fertility levels). Eventually, everyone will benefit from globalisation ('trickle down') and technologically advances will remedy ecological problems even with little or no government interference ('Environmental Kutznetz Curve'). Examples of this type of scenario include the A1 scenario (IPCC), the Markets First scenario (UNEP), Market Forces (GSG) or the Optimistic scenario (IFPRI). The underlying worldview expresses the arguments in Fukuyama's (1992). 'The End of History'. Many historical trends and periods can be interpreted as support for such scenarios, e.g. the role of artificial fertiliser that have allowed a much larger world food production and the subsequent replacement of cleaner and more convenient fuels and technologies in the energy system. Scenarios in this family, however, tend to show high levels of environmental pressure (e.g. greenhouse gas emissions or land use), despite the high level of efficiency driven by rapidly increasing consumption and production patterns. A major risk of this scenario family is thus that the ecological and social systems are much more sensitive than assumed, as a result of which feedbacks become important. More or less optimistic and pessimistic elaborations with respect to the impacts of the environmental pressure thus exist.

\subsection{Reformed market scenarios}

Scenarios in this family have similar basic philosophy as the first set, but include some additional policy assumptions aimed at correcting market failures with respect to social development, poverty alleviation or the environment. As such, the "free market" is accompanied by effective market regulation to prevent market failures. Examples of this type of scenarios include the Policy First scenario (UNEP), Policy Reform (GSG) or the Global Orchestration

Table 3

Key assumptions in different 'scenario families'.

\begin{tabular}{|c|c|c|c|c|c|c|}
\hline & Economic optimism & Reformed markets & Global SD & $\begin{array}{l}\text { Regional } \\
\text { competition }\end{array}$ & Regional SD & Business-as-usual \\
\hline Economic development & Very rapid & Rapid & $\begin{array}{l}\text { Ranging from slow } \\
\text { to rapid }\end{array}$ & Slow & $\begin{array}{l}\text { Ranging from } \\
\text { mid to rapid }\end{array}$ & Medium (globalisation) \\
\hline Population growth & Low & Low & Low & High & Medium & Medium \\
\hline Technology development & Rapid & Rapid & $\begin{array}{l}\text { Ranging from mid } \\
\text { to rapid }\end{array}$ & Slow & $\begin{array}{l}\text { Ranging from } \\
\text { low to rapid }\end{array}$ & Medium \\
\hline Main objectives & Economic growth & Various goals & Global sustainability & Security & Local sustainability & Not defined \\
\hline Environmental protection & Reactive & $\begin{array}{l}\text { Both reactive and } \\
\text { proactive }\end{array}$ & Proactive & Reactive & Proactive & Both reactive and proactive \\
\hline Trade & Globalisation & Globalisation & Globalisation & Trade barriers & Trade barriers & Weak globalisation \\
\hline Policies and institutions & $\begin{array}{l}\text { Policies create } \\
\text { open markets }\end{array}$ & $\begin{array}{l}\text { Policies reduce } \\
\text { market failures }\end{array}$ & $\begin{array}{l}\text { Strong global } \\
\text { governance }\end{array}$ & $\begin{array}{l}\text { Strong national } \\
\text { governments }\end{array}$ & $\begin{array}{l}\text { Local steering; } 1 \\
\text { ocal actors }\end{array}$ & Mixed \\
\hline
\end{tabular}

Note: This table summarises key assumptions in very general terms. Where differences within a set of scenario families exist, broad ranges are indicated. 
scenario (MA). Here, too, there are quite vivid illustrations of the plausibility of such scenarios, e.g. the extensive environmental regulations that have been introduced in most high-income countries. The uncertainties and controversies are about how much can be achieved by market regulation and technology inducement without changing the overall "market" paradigm. In a sense, one may argue that this scenario family is an optimistic subset of the first category - but given the different focal question, we distinguish it here as a separate category. A critical question within this scenario family is how much society is able to prevent environmental degradation and meet social goals without a major reform as of the underlying paradigm.

\subsection{Global sustainable development scenarios}

This family of scenarios has a strong orientation towards environmental protection and reducing inequality, based on solutions found through global cooperation, lifestyle change and more efficient technologies. Central elements are a high level of environmental and social consciousness combined with a coherent global approach to sustainable development. Within this scenario family, it is assumed that a high level of international governmental coordination is necessary and possible in order to deal with international problems like poverty alleviation, climate protection and nature conservation. As in the Reformed Market family, it entails regulation of markets but at a global scale and with global coordination and based on the conviction that the earth's limits are in sight and that therefore pro-active policies are necessary. Examples of this type of scenario include the B1 scenario (IPCC), the Sustainability First scenario (UNEP), Great Transition (GSG) or the TechnoGarden scenario (MA). Key questions are how effective such global coordination and policies can be, in view of the known threats of bureaucracy and corruption and also how major transition processes can be initiated and sustained.

\subsection{Regional competition/regional markets scenarios}

Scenarios in this family assume that regions will focus more on their more self-reliance, national sovereignty and regional identity, leading to diversity but also to tensions among regions and/or cultures. Countries are concerned with security and protection, emphasizing primarily regional markets and paying little attention to common goods. Huntington's (1996) 'Clash of Civilization' is often interpreted as the underlying worldview. Examples of this type of scenario include the A2 scenario (IPCC), the Security First scenario (UNEP), Fortress World (GSG), the Pessimistic scenario (IFPRI) or the Order from Strength scenario (MA). Among the more extreme scenarios are the conflict scenarios identified by the GSG (barbarization). A key issue in these scenarios is how much selfreliance is possible without becoming harmfully ineffective with respect to supranational issues of resource depletion and environmental degradation. The category, like others, includes different variants - but these are rarely optimistic with respect to global poverty reduction and environmental protection. Among the more extreme scenarios are the conflict scenarios identified by the GSG (barbarization).

\subsection{Regional sustainable development scenarios}

The regional sustainability scenario assumes that globalisation and international markets loss of traditional values and social norms - but, in a different strand, to senseless consumerism and disrespect for life. Citizens and countries must each take on the responsibilities they can bear, providing aid or setting a green example to the rest of the world, from a sense of duty, out of conviction or for ethical reasons or to solve primarily your own problems. The focus is on finding regional solutions for current environmental and social problems, usually combining drastic lifestyle changes with decentralization of governance. International institutions decline in importance, with a shift towards local and regional decision-making structures and institutions. This worldview is well represented by Schumacher's (1973) book 'Small is beautiful'. The Eco-Communalism scenario of the GSG is a clear example of this scenario family. Based on their storylines, one would also expect the B2 scenario (IPCC) or the Adapting Mosaic scenario (MA) to fall into this category. However, because integrated assessment models tend to focus on global trends and generic mechanisms, scenarios in this family are usually badly quantified (de Vries, 2006). Remedying this situation is cumbersome and data- and labour-intensive. Therefore, this scenario family is often constructed with "intermediate" assumptions for all drivers in all regions, which results in a typical "intermediate scenario" that, based on the quantification, is better characterized as business-as-usual scenario. This is the case for the B2 scenario and, to some degree, for the Adapting Mosaic scenario.

\subsection{Business-as-usual/intermediate scenarios}

The scenarios within this family basically assume that the future can be characterized by a continuation of historical trends. This does not mean that no changes would occur: similarly as in the past society is assumed to respond to emerging problems, for instance with respect to energy and land scarcity. The main scenario assumption, however, are not derived from a storyline that deliberately emphasizes a specific "extreme" position, but from a storyline that assumes that historical dynamics will also be guiding the future. In quantitative terms, this often translates into "intermediate" value. The business-as-usual seems often attractive to use. This is partly because it is often regarded as more plausible: this scenario may result from the interaction of trends going in more extreme directions in other scenarios. Such a dynamic of centrifugal and centripetal forces are also recognizable in long-term societal dynamics (van Egmond and de Vries, 2011). A second rationale is that scenario analysts may be more interested in policy-responses than in baseline development themselves. As such, this scenario type is often used as a reference (or even "counterfactual") scenario for the policy-scenario approach (some practitioners seem to assume that in such a way, they make their assessment less subjective. This is, however, a debatable assumption that we discuss further in Section 4). In those cases, the scenarios tend to be formulated assuming no (or relatively little) new policies for the issue at focus (as a contrast to the policy-cases). The scenarios are therefore often "intermediate" scenarios for most assumptions, but tend to freeze policy for the issues that the scenario focuses on. It should be noted that the distinction between different policies is not always straightforward. For example, while climate scenarios in this category will normally exclude climate policy, they will include "energy policy"; this raises difficult questions on whether certain measures like promotion of renewables are primarily 'climate policy' or 'energy policy' measures.

There is some debate whether this last category should be seen as a scenario family, or in fact even a scenario. In our opinion, however, the assumption that the future can be characterized on the basis of historical trends provides a similar type of conditional storyline as the other scenario families. Adding this category to the set of scenario families seen in the literature also helps in classifying the literature better. At the same time, we realize that this type of scenarios clearly differs from the others in the sense that its storyline is often less well elaborated. Examples of this type of scenario include the IEA energy outlook and the OECD Environmental Outlook. The use of business-as-usual scenarios is sometimes seen as inferior, given the implicit assumptions and 
Table 4

Recent scenario-based assessments mapped against 'scenario families'.

\begin{tabular}{|c|c|c|c|c|c|c|c|}
\hline & IPCC-SRES & UNEP GEO-3 & GSG & MA & IFPRI & FAO & OECD \\
\hline $\begin{array}{l}\text { Conventional markets/ } \\
\text { Economic optimism }\end{array}$ & $\mathrm{A} 1 / \mathrm{A} 1 \mathrm{~T} / \mathrm{A} 1 \mathrm{~B}$ & Markets first & Conventional worlds & & Optimistic scenario & & \\
\hline Reformed markets & & Policies first & Policy reform & Global orchestration & & & Policy-variants \\
\hline Global SD & B1 (B1-450) & Sustainability first & New sustainability paradigm & Techno garden & & & \\
\hline Regional competition & A2 & Security first & Barbarisation & Order from strength & Pesimistic scenario & & \\
\hline Regional SD & $B 2^{a}$ & & Eco-communalism & Adapting aosaic & & & \\
\hline Business-as-usual & $B 2^{\mathrm{b}}$ & & & & Reference scenario & FAO AT2020 & Reference \\
\hline
\end{tabular}

Note: Italics are used to indicate that scenarios are not completely consistent with the group in which it is categorised.

a Storyline

b Quantification.

the lower attention to uncertainty. This runs a risk of "stealth advocacy" (Pielke, 2007) if these implicit assumptions (e.g. preference for financial instruments) influence the results.

In Table 4, we have indicated how the scenarios in the assessment map upon the scenario families. In many cases, these map well into the scenario families. In some other cases, however, the scenarios of the different assessments do not nicely fit into the scheme. For instance, some of the regional sustainable development scenarios can also be interpreted in the "business-as-usual/ intermediate" category (see above). Also, the IPCC B1 scenario is not unambiguous because it is built on a somewhat unlikely combination of strong environmental policy but no climate policy as a consequence of the IPCC mandate.

There might be several reasons for the occurrence of these scenario families. First of all, assessments obviously build upon each other. Information of previous assessments is read by the developers of new scenarios and consciously or unconsciously used. Such forwarding of information also occurs as a limited set of researchers participate in several scenario exercises (Leemans, 2008). Several assessments even actively refer back to the scenarios developed elsewhere. For policy-making support this is may have some advantages: it increases comparability across reports and makes sure that each report simply adds new information on the issue at stake to the existing scenarios. The disadvantage, however, might be that it reduces creativity. An example of the re-use of existing scenarios is UNEP's Third Global Environmental Outlook (and thus also the Fourth Outlook), the pedigree of these scenarios being the Global Scenario Group and the IPCC SRES scenarios. For other assessments, such as the MEA, such direct link is not indicated in the report. In contrast, some of the authors of the MEA raised the question whether the fact that earlier scenarios paid only limited attention to the role of ecosystems would imply that their storylines would be inconsistent given the likely occurrence of feedbacks from ecological changes (Cumming et al., 2005b). The final MEA scenarios, however, do link back reasonably well to earlier scenarios.

In some way, the reoccurrence of the same scenario families in different assessments can be interpreted as proof of their relevance (or saliency). An argument discussed by de Vries and Petersen (2009) is that the SRES scenarios (and, therefore, also the other scenarios that form part of the same family) can be associated with different worldviews as identified in the Cultural Theory (Rayner, 1992; Thompson et al., 1990). Using a slightly different categorization than de Vries and Petersen, the individualistic worldview coincides with the Economic Optimism family; egalitarian worldview with that of the regional and/or global sustainable development view and the hierarchistic worldview with reformed markets view. One may argue that this linkage does provide a more generic basis for the scenario families, as the Cultural Theory has been presented as a time-independent description of actors within society. Earlier, Rotmans and de Vries (1997) explicitly used the Cultural Theory for their scenario storylines. However, the generic application of the Cultural Theory has been challenged and the interpretation and subsequent quantification of the worldviews still leaves considerable freedom. As such, the occurrence of these scenario families should be seen more as an empirical observation about the current scenario literature than a claim that together these would be representative of all relevant possible futures.

Obviously, the fact that the scenario families exist in the literature does not mean that either of them is feasible. Earlier also Rotmans and de Vries (1997) confronted scenario storylines with different assumptions on the resilience of the environmental system showing that some combinations are inconsistent (in fact looking at risk in scenario context is an important reason to develop them). This has become the more relevant, now that empirical evidence of catastrophic change in socialecological systems due to non-linear feedbacks is mounting (Scheffer, 2009). Just as one should not claim that all scenario families are feasible, it is also very well possible that other scenario families exists (that are for instance used in other studies than the GEAs looked at).

A final observation is that in each family positive and negative scenarios may occur. For instance, the economic optimism world might have successful variants assuming that environmental feedbacks are small - but rather unsuccessful, disaster scenarios if feedbacks are strong. While these different aspects of the same scenario can clearly be found in the literature - it should be noted that little "disaster" scenarios can be found in the literature. Reasons for this include the limitations in knowledge and available modeling tools, the influence of government review and the usefulness of scenarios. The impact of model limitations relates to the fact that most models focus on smooth trends (given the large uncertainties that surround non-linearities). The influence of government review captures the fact that disaster scenarios are typically controversial and therefore are assumed not to survive government approvement processes. Finally, many scenario developers find scenarios that only include negative aspects of less use and therefore do not include those in a set with a small number of scenarios.

\section{Discussion: explorative scenarios versus policy-scenarios and implications for future assessments}

\subsection{Explorative scenarios versus policy-scenarios}

We observed that the explorative scenario approach has been very popular in GEAs published between 2000 and 2005, but that more recent assessments have instead used the policy scenario approach. This shift is relevant given the strengths and weaknesses of both approaches. In fact, in many scenario studies there is quite a vivid discussion about the choice between these two methods. It is therefore worthwhile to discuss this specific issue further and draw lessons for future assessments. 
4.1.1. What are strengths and weaknesses of both approaches?

First-of-all, strengths of the explorative approach are: it (i) stimulates imagination and creativity in thinking about the future; (ii) deals with the inherent uncertainties and different value judgments related to unstructured problems; and (iii) helps to identify broad responses categories within a certain context as a way to develop robust policies. The approach is especially useful for more strategic questions in case policy-targets have not been clearly defined yet - or when it is not even clear how severe a certain problem is. There are, however, also weaknesses. The explorative approach often lacks focus and is not focused on specific policy-options. Moreover, storylines can be regarded as explorative.

The first strength of the policy scenario approach is that it significantly simplifies the analysis and is directly policy-relevant. The approach has a high degree of transparency, but it risks reduced focus on fundamental uncertainties. This is true for the baseline (often a single business-as-usual case) as well as for the policy scenarios (often variants with just one or a few policy interventions). In fact, the approach often pretends that options can be objectively evaluated on the basis of a single set of criteria (often cost-effectiveness) without communicating that these criteria themselves are worldview dependent.

\subsubsection{What could cause a shift in approach?}

Before going further, a first question is whether the observed shift in the choice between these methods in international assessments is a real trend or merely the haphazard outcome of observations from a limited data set? And, if it is a real trend, what is causing it?

The first explanation is that the shift in scenario method is caused by a more general shift in focus in international environmental policy-making. A classical distinction in phases of policy-making was introduced by Winsemius (1986, 1990), recognizing four phases: (1) problem recognition, (2) policy formulation, (3) policy implementation and (4) control (obviously, in reality, the sequence of these phases may not be a linear process). In each phase, there are different information needs (as also indicated by van Daalen et al., 2002). The problem recognition phase focuses on getting an issue on the political agenda. Key questions are of explorative nature: What may happen? What risks may occur? What are the major causes? In the second phase, the focus is on formulating responses. In this phase, information needs focus on questions like: What targets should we strive for? What is needed to reach certain targets? In the third phase (implementation) some form of consensus on the policy response has been reached. Key question now: Are policies really being implemented? Are they effective? Are there any secondary impacts? Finally, in the control phase, finally, the information needs shift towards monitoring progress.

In this context, it is interesting to note that the mandate for developing the IPCC SRES scenarios in the field of climate change explicitly excluded the analysis of policy options (Girod et al., 2009), confirming the problem recognition focus of this exercise. For the new climate scenarios, Moss et al. (2010) in contrast explicitly indicate that a main motivation for developing new scenarios is to look into the role of policy (going to a policy formulation phase). Compared to 1996 (when the SRES work started), many countries have formulated ambitious climate targets that will require policies. The same trend towards policy analysis can be noted in the scientific literature on climate scenarios. Also the second OECD Environmental Outlook explicitly indicates its focus on exploring mitigation options (OECD, 2008). Similarly, in the mandate of GEO-5 now a choice has been made to move away from the explorative approach to the policy-scenario approach to provide a more direct support for environmental policy-making (UNEP, 2009). To some degree, this explanation may be challenged by the question whether indeed so much progress in policy-making (moving from an explorative to problem solving phase) has been made explaining a complete change in research focus.

For the second explanation we use the IAASTD as an example. Here, the original decision was to elaborate the four existing scenarios from the MEA with respect to their relevance for the agricultural sector (thus following the explorative approach). Halfway the process, this decision was reversed based on discussions between the assessment's advisory board and the authors. Criticism on the original approach focused on three elements: (1) the usefulness of the explorative approach (too arbitrary); (2) the complexity of the scenarios (too complex); and (3) the normative character of the scenarios (too political). While the first criticism is connected with the need for a stronger policy focus (previous explanation), the next two are not. Both points have been expressed before (Parson et al., 2007). The explorative approach clearly risks a lack of transparency in complicated storylines and logic. The third point is related to interpretation and use of scenarios by political actors. While explorative scenarios are meant to encourage debate, societal actors respond to them based on their specific interest. For instance, the IPCC SRES B1 scenario (see Section 3) was strongly criticized by some environmental NGOs as it would suggest that autonomous developments could also lead to a (modest) reduction of emissions. Another example concerns the final approval sessions of the decision-makers summary of UNEP's GEO-4: here countries rejected some of the scenario analyses in the main report (UNEP, 2009) with the argument of lack of transparency and normative assumptions. The thing to note is that societal actors often respond to specific scenarios and not to the set as a whole and that the responses often coincide with the political and/or economic interests of these actors. Clearly, it remains an interesting area for social science to analyze how various types of scenarios are perceived and how this influences the credibility, saliency and legitimacy of the outcomes (Garb et al., 2008).

A third possible explanation points at the shift in preferred research methods across different scientific disciplines. For instance, the policy scenario approach is popular in economic sciences, which is used at focusing on the impacts of a specifically described intervention. As such, a shift in disciplinary involvement (possibly related to the policy lifecycle discussed earlier) might also lead to a shift in scenario preference. However, there is little further evidence to support this hypothesis.

\subsubsection{What are the implications of a shift in approach?}

It is important to realize that only using the single baseline/ variant approach does constitute an important risk: by not identifying some of the major fundamental uncertainties society is facing, the scenario results may only be true under a limited set of assumptions and falsely suggest that we know the future. It reduces the focus on the importance of other policies than strictly environmental and pays too little attention to differences in worldview. This becomes worse if the assumptions made implicitly in the baseline and the model simulations are worldview dependent. One could think of several examples where the context might actually be more important that the "environmental policy" itself. For instance, climate change impacts and the appropriate adaptation measures might be very different in a future with a lot of economic growth and technological progress (increasing adaptive capacity) than in a situation with a lot of poverty and poor governance (and thus low adaptive capacity). Also instruments like global emission trading could be effective in some context, but totally ineffective in another context (e.g. in a regional competition world). Similarly, relevant actors to deal with issues 
related to hunger are very different depending on the socioeconomic storyline. We therefore propose to add at the very least at a form of robustness analysis to each "baseline/variant" type approach. Such analysis could be based on the scenario families identified in this paper in existing studies. Examples of such studies are for instance the 2nd National Sustainability Outlook of the Netherlands (de Vries and Petersen, 2009; MNP, 2007). In general, this will result in more pluralistic policy-responses.

Another way to deal with this is to develop scenario sets that include both extreme, explorative scenarios and a more intermediate (business-as-usual) scenario. This contrasts somewhat with earlier ideas that there should not be a central scenario to avoid the preference of using only the central case. However, the disadvantage of not presenting a central case is that users might decide themselves which single scenario is used for this purpose (e.g. the B2 scenario of the IPCC). The current proposals for new climate scenarios (SSPs), therefore, include a real central scenario (Arnell et al., 2011).

Finally, the two scenario approaches also have implications for stakeholder involvement. In the explorative approach, stakeholders can trust that most of the relevant worldviews and uncertainties are considered. For the policy scenarios, stakeholder can contribute to the identification, evaluation and prioritization of policies by analyzing policy strategies and indicate were alternative pathways need be developed because of disagreement. By raising involvement of stakeholders, however also the danger of unbalanced influences can increase. Especially wishful thinking in favor of the interests of certain stakeholders would lead to drawbacks regarding the criteria of saliency and credibility. Therefore, the organization of the process of participation is crucial.

\subsection{Lessons for future scenario assessments}

Based on the overview of scenario applications in GEAs provided in the paper, there are several observations that are interesting to consider in future assessments.

First of all, consistent scenario families can be recognized in existing assessments. It seems useful in future scenario assessments to consider how useful these families are for the problem at hand. Instead of developing new storylines, researchers may decide to use existing families. Alternatively, a developer of new scenarios may want to indicate how new scenarios relate to the existing families, making it easier for users to relate information of different assessments. A useful example in this respect is the work on new climate scenarios (Moss et al., 2010; van Vuuren et al., 2012; Van Vuuren et al., 2011). Here, indeed attempts are made to relate the new storylines (called shared-socio-economic pathways or SSPs), among others to keep a link between existing work based on SRES or the MEA scenarios and the new scenario work.

Second, we believe that GEAs have to broaden expertise involved towards social sciences. In most GEAs, the social-science input is relatively low. Still, this type of expertise can contribute to strengthening the scenarios in many respects. This goes for theoretical perspectives on international relations that shed different light on prospects and avenues for international cooperation to solve global environmental problems, psychology and sociology on values and preferences and anthropologists to make scenarios less culturally biased. The most important issue is that of policy implementation: while GEAs generally show that sufficient potential exists to move towards more sustainable development routes, this potential is often not used. A key question, therefore, which policies support the required transformative pathways.

Third, GEAs may want to improve the communication of scenarios. Several papers discussing the GEAs indicate that GEAs pay relatively little attention to the 'hand-off' of information to the users. An important reason is that the user group is diffuse. A consequence, however, is that GEAs may be underused. Future GEAs may think off improving this by: (1) considering a more focused user group and/or (2) consider forms of communication other than reports.

Fourth, as argued in this article, the explorative and policyoriented scenario approach have both strength and weaknesses. There is some evidence that currently the policyoriented approach has gained prominence, but at the costs of representing uncertainty. In that light, it is useful to combine elements of the two approaches in order to strengthen assessments (de Vries, 2001). In the process to develop the new IPCC scenarios, it is done in the form of a scenario matrix with one axis representing different policy interventions and a second axis representing different storylines (van Vuuren et al., 2012).

Fifth, it should be noted that the set of published GEA scenarios is very long. Each GEA has somehow a unique position based on its focus, user group or method. However, it seems important to consider whether in the future some GEAs can be better organized vis-à-vis each other, to avoid overlap, certainly those associated with various UN organizations. In that light, several sectoral assessment may provide input into a limited set of more general, "flagship" assessments.

\section{Conclusions}

A large number of GEAs have been published in the last few years that have used scenarios to explore possible future environmental change. In this paper, we have compared the use of scenarios across these assessments. This overview has led to the following conclusions.

First of all, together the GEAs published in the last 10 years provide a rich body of information about possible developments with respect to environmental issues. Some of the assessments that have been published overlap in their scope. Other assessments focus on specific issues - for instance looking specifically into certain environmental issues (e.g. land use, agriculture, water) or regions (the BRIC countries in the OECD environmental outlook).

Second, the scenarios used in the assessments can be grouped into a set of 6 scenarios families. Nearly all scenarios used in the different assessment can be convincingly grouped into 6 main scenario families. Recognizing these families makes it easier to relate and combine the information of different assessments and can help structure the debate about strategic directions for environmental policies.

Third, an important (but not always clear-cut) distinction between the scenarios used in the assessments is the explorative scenario and the policy-scenario approach. The first is mostly oriented at strategic questions, exploring possible futures. The second approach focuses on the impact of specific policy options and is particular useful if policy targets have been formulated. The two approaches have clear strengths and weaknesses. Most GEAs in the period 2000-2007 have used the explorative scenario approach. Since that period, however, most assessments have used the second approach. There could be different reasons for this shift, but it might also be just coincidental. One possible reason is related to focus in the debate from problem recognition to formulation of response strategies.

Fourth, while the policy-scenario approach can often be more relevant in identifying response strategies, the risk of using only this approach is an under representation of pluralism and uncertainty. The explorative scenario approach is designed to explore different possible development trajectories, also in relation to different worldviews. The policy-scenario approach 
often only uses a single baseline scenario. In avoid to avoid that too little attention is paid to uncertainty, we would like to argue that it might be useful to add at the very least at a form of robustness analysis to each "baseline/variant" type approach. Another way to deal with this is to develop scenario sets that include both explorative scenarios - and an intermediate scenario as a basis for policy variants.

Fifth, it seems useful to make sure that a diversity of approaches is used future GEAs. In this paper, several different types of scenarios have been discussed. Each of the methods have strengths and weaknesses. Some scenario approaches can directly support decision-making, while others contribute to more strategic thinking about the future (and might even stimulate debate). In determining the appropriate method for each individual GEA, it is important to clearly define the issue at stake in terms of (1) relevant policy question, (2) the stage of decision-making, and (3) the degree of societal consensus.

\section{Acknowledgements}

The first author acknowledges the financial support of the FP7 RESPONSES project of the European Commission. It should be noted that several authors have participated in the exercises described in this paper.

\section{References}

Arnell, N., et al., 2011. A Framework for a New Generation of Socioeconomic Scenarios for Climate Change Impact, 2 Adaptation, Vulnerability, and Mitigation Research. , http://www.isp.ucar.edu/sites/default/files/Scenario_FrameworkPaper_15aug11_0.pdf.

Ash, N., 2010. Ecosystems and Human Well-Being. A Manual for Assessment Practitioners. Island Press, Washington, DC

Bruinsma, J., 2003. World Agriculture: Towards 2015/2030, An FAO Perspective. Food and Agriculture Organisation (FAO), Rome, Italy.

CA, 2007. Water for Food, Water for Life: A Comprehensive Assessment of Water Management in Agriculture. Earthscan, London.

Carpenter, S., Pingali, P., 2005. Millennium Ecosystem Assessment - Scenarios Assessment. Island Press, Washington, DC.

Cash, D.W., et al., 2003. Knowledge systems for sustainable development. Proceedings of the National Academy of Sciences of United States of America 100, 80868809.

Clark, W.C., Mitchell, R.B., Cash, D.W., 2006. Evaluating the influence of Global Environmental Assessments. In: Mitchell, R.B., Clark, W.C., Cash, D.W., Dickson, N.M. (Eds.), Global Environmental Assessments: Information and Influence. MIT Press, Cambridge.

Cosgrove, W., Rijsberman, F., 2000. World Water Vision: Making Water Everybody's Business. World Water Council/Earthscan Publication, London.

Cumming, G.S., et al., 2005a. Are existing global scenarios consistent with ecological feedbacks. Ecosystems 8 (143-152).

Cumming, G.S., et al., 2005b. Are existing global scenarios consistent with ecological feedbacks? Ecosystems 8 (2), 143-152.

de Vries, H.J.M., 2001. Perceptions and risks in the search for a sustainable world - a model-based approach. International Journal of Sustainable Development 4(4), 434-453.

de Vries, H.J.M., 2006. Scenarios: guidance for an uncertain and complex world. In: Constanza, R., Graumlich, L.J., Steffen, W. (Eds.), Sustainability or Collapse? An Integrated History and Future of People on Earth. MIT Press, Cambridge, USA.

de Vries, B.J.M., Petersen, A.C., 2009. Conceptualizing sustainable development. Ecological Economics, http://dx.doi.org/10.1016/j.ecolecon.2008.11.015.

Dreborg, 1996. Essence of backcasting. Futures 28 (9), 813-828.

FAO, 2006. World Agriculture: Towards 2030/2050. Prospects for Food, Nutrition, Agriculture and Major Commodity Groups. Food and Agriculture Organization of the United Nations, Rome.

Fukuyama, F., 1992. The End of History and the Last Man. Free Press, New York.

Garb, Y., Pulver, S., van Deveer, S., 2008. Scenarios in society, society in scenarios: toward a social scientific analysis of storyline-driven environmental modelling. Environmental Research Letters (3), 045015.

Girod, B., Wiek, A., Mieg, H.A., Hulme, M., 2009. The evolution of the IPCC's emissions scenarios. Environmental Science and Policy 12 (2), 103-188.

Henrichs, T., et al., 2010. Scenario development and analysis for forward-looking ecosystem assessments. In: Ash, N. (Ed.), Ecosystems and Human Well-Being. A Manual for Assessment Practitioners. Island Press, Washington, DC.

Hulme, M., Dessai, S., 2008. Predicting deciding, learning: can one evaluate the 'success' of scenarios? Environmental Research Letters 4 (3), 1-7.

Huntington, S.P., 1996. The Clash of Civilizations and the Remaking of World Order. Simon \& Schuster, New York

IEA, 2008. World Energy Outlook 2008. IEA, Paris.
IPCC, 2001. Climate Change 2001: Synthesis Report. Cambridge University Press, Cambridge.

IPCC, 2007. Climate Change 2007 - Synthesis Report. Contribution of Working Groups I, II and III to the Fourth Assessment Report of the Intergovernmental Panel on Climate Change. Cambridge University Press, Cambridge.

Jäger, J., Areola, M.E., Chenje, M., Pinter, L., Raibhandari, P., 2009. IEA Training Manual. A Training Manual on Integrated Environmental Assessment and Reporting. United Nations Environmental Programme, Nairobi.

Kahn, H., Wiener, A.J., 1967. The Year 2000. A Framework for Speculation on the Next Thirty-Three Years. MacMillan, New York.

Kok, M.T.J., et al., 2008. Lessons from Global Environmental Assessments. Netherlands Environmental Assessment Agency, Bilthoven.

Kok, M., et al., 2009. Environment for Development - Policy Lessons from Global Environmental Assessments. Netherlands Environmental Assessment Agency, Bilthoven, The Netherlands.

Leemans, R., 2008. Personal experiences with the governance of the policy-relevant IPCC and Millennium Ecosystem Assessments. Global Environmental Change 18 (1), 12-17.

Leggett, J., Pepper, W., Swart, R., 1992. Emissions scenarios for the IPCC: an update. In: Houghton, J.T.e.a. (Ed.), Climate Change 1992. Cambridge University Press, Cambridge.

MA, 2005. Millennium Ecosystem Assessment - Synthesis Report. Millennium Ecosystem Assessment.

Major, E., Cordey-Hayes, M., 2000. Knowledge translation: a new perspective on knowledge transfer and foresight. Foresight 2 (4), 411-423.

Meadows, D.H., Meadows, D.L., Randers, J., Behrens, W.W., 1972. The Limits to Growth: A Report to The Club of Rome. Universe Books, New York, USA, 205 pp.

Mitchell, R.B., Clark, W.C., Cash, D.W., Dickson, N.M., 2006. Global Environmental Assessments: Information and Influence. MIT Press, Cambridge, USA.

MNP, 2007. Tweede Duurzaamheidsverkenning; 1 ; Nederland en een duurzame wereld: armoede, klimaat en biodiversiteit. Milieu- en Natuurplanbureau, Bilthoven.

Moss, R.H., et al., 2010. The next generation of scenarios for climate change research and assessment. Nature 463, 747-756.

Nakicenovic, N., et al., 2000. Special Report on Emissions Scenarios: A Special Report of Working Group III of the Intergovernmental Panel on Climate Change. Cambridge University Press, Cambridge.

Nakicenovic, N., et al., 2003. IPCC SRES revisited: A response. Energy and Environment 14(2-3), 187-214.

Nowotny, H., 2008. Insatiable Curiosity: innovation in a Fragile Future. MIT Press, Cambridge, MA.

NRC, 2007. Analysis of Global Change Assessments: Lessons Learned. Committee on Analysis of Global Change Assessments National Research Council/The National Academies Press, Washington, DC.

O'Neill, B.C., 2004. Conditional probabilistic population projections: an application to climate change. International Statistical Review 72 (2), 167-184.

OECD, 2008. OECD Environmental Outlook to 2030. OECD, Paris.

Parson, E.A., 2008. Use global-change scenarios: current issues and challenges. Environmental Research Letters 3, 045016.

Parson, E., et al., 2007. Global Change Scenarios: Their Development and Use. Subreport 2.1B of Synthesis and Assessment Product 2.1 U.S. Climate Change Science Program and the Subcommittee on Global Change Research. Department of Energy. Office of Biological \& Environmental Research, Washington, DC.

Pielke, R., 2007. The Honest Broker. Cambridge University Press.

Pulver, S., van Deveer, S., 2009. Thinking about tomorrow: scenarios, social science and global environmental politics. Global Environmental Politics 9 (2), 1-13.

Raskin, P.D., 2005. Global scenarios: background review for the Millennium Ecosystem Assessment. Ecosystems 8, 133-142.

Raskin, P., et al., 2002. Great Transition: The Promise and Lure of the Times Ahead. Stockholm Environmental Institute, Boston.

Raskin, P., Monks, F., Ribeiro, T., van Vuuren, D.P., Zurek, M., 2005. Global scenarios in historical perspective. In: Carpenter, S., Pingali, P. (Eds.), Millennium Ecosystem Assessment - Scenarios Assessment. Island Press, Washington, DC.

Rayner, S., 1992. Cultural theory and risk analysis. In: Preagor, G.D. (Ed.), Social Theory of Risk. Westport, USA.

Richels, R.G., Manne, A.S., Wigley, T.M.L., 2004. Moving Beyond Concentrations: The Challenge of Limiting Temperature Change. Working Paper No. 04-11, AEIBrookings Joint Center, Washington DC.

Robinson, J., 1982. Energy backcasting: a proposed method of policy analysis. Energy Policy 10 (4), 337-344.

Robinson, J.B., 1990. Futures under glass. A recipe for people who hate to predict. Futures. October, 820-842.

Rothman, D.S., van Bers, C., Bakkes, J.A., Pahl-Wostl, C., 2009. How to make global assessments more effective: lessons from the assessment community. Current Opinion in Environmental Sustainability 1, 214-218.

Rotmans, J., de Vries, B. (Eds.),1997. Perspectives on Global Change - The TARGETS Approach. Cambridge University Press, Cambridge, UK.

Scheffer, M., 2009. Critical Transitions in Nature and Society. Princeton University, Princeton.

Schumacher, E.F., 1973. Small is beautiful: Economics as if people mattered. Harper \& Row, New York.

Thompson, M., Ellis, R., Wildavsky, A., 1990. Cultural Theory. Westview Press, Boulder, USA.

UNEP, 2002. Global Environment Outlook 3. EarthScan, London.

UNEP, 2006. Africa Environment Outlook 2 - Our Environment, Our Wealth. United Nations Environment Programme, Nairobi.

UNEP, 2007. Global Environment Outlook 4. UNEP, Nairobi. 
UNEP, 2009.In: Twenty-Fifth Session of the Governing Council/Global Ministerial Environment Forum. Decisions of the Governing Council/Global Ministerial Environment Forum at its Twenty-Fifth Session. Decision 25/2: III Future Global Assessment of Environmental Change, United Nations Environmental Programme, Nairobi, 16-20 February.

UNEP, 2010a. Latin America and the Caribbean Environment Outlook. GEO LAC 3. United Nations Environment Programme, Nairobi.

UNEP, 2010b. Environment Outlook for the Arab Region. Environment for Development and Human Well-being, United Nations Environment Programme, Nairobi.

van Asselt, M.B.A., Faas, A., van der Molen, F. and Veenman, S.A., 2010. Uitzicht, Wetenschappelijke raad voor het regeringsbeleid (WRR), Den Haag.

van Daalen, C.E., Dresen, L., Janssen, M.A., 2002. The roles of computer models in the environmental policy life cycle. Environmental Science \& Policy 5 (221-231).

van Egmond, N., de Vries, B., 2011. Sustainability: the search for the integral worldview. Futures 43, 853-867.

van Vuuren, D.P., 2007. Energy Systems and Climate Policy: Long-term Scenarios for an Uncertain Future. PhD Thesis, Utrecht University. van Vuuren, D.P., de Vries, B., Beusen, A., Heuberger, P.S.C., 2008. Conditional probabilistic estimates of 21st century greenhouse gas emissions based on the storylines of the IPCC-SRES scenarios. Global Environmental Change 18 (4), 635-654.

Van Vuuren, D.P., et al., 2011. Representative Concentration Pathways: An overview. Climatic Change 109 (1), 5-31.

van Vuuren, D.P., et al., 2012. A proposal for a new scenario framework to support research and assessment in different climate research communities. Global Environmental Change 22 (1), 21-35.

Watson, B. (Ed.), 2008. International Assessment of Agricultural Science and Technology Development.

Wilkinson, A., Eidinow, E., 2008. Evolving practices in environmental scenarios: a new scenario typology. Environmental Research Letters 3, 045017.

Winsemius, P., 1986. Gast in Eigen Huis: Beschouwingen over Milieumanagement. Tjeenk Willink, Alphen a/d Rijn, The Netherlands.

Winsemius, P., 1990. Guests in Our Own Home. McKinsey \& Company, Amsterdam, The Netherlands. 